\title{
Defining Remission in Psoriatic Arthritis: Are We Getting Closer?
}

New paradigms in the management of psoriatic arthritis (PsA) are gaining great acceptance in the rheumatology community, including early treatment ${ }^{1}$, remission as a treatment objective ${ }^{2}$, assessment of all domains involved ${ }^{3}$, and frequent measuring of disease activity and adjusting therapy accordingly (treat to target $)^{4}$.

To achieve these goals, we need effective therapies. The introduction of biologic therapies, mainly tumor necrosis factor inhibitors ( $\mathrm{TNFi}$ ), has greatly improved our ability to treat the various manifestations of PsA.

These various manifestations include peripheral and axial joint, skin, and nail involvement; enthesitis and dactylitis being among the more frequent ones. It is important to gather data for all these clinical features to assess disease activity. Remission criteria and activity indexes borrowed from rheumatoid arthritis (RA) have been used in PsA, but they clearly are unable to include all PsA manifestations ${ }^{2,5,6}$. Composite measures combine several dimensions of disease status, often by combining these different domains into a single score. Such indices seem to be more efficient than unidimensional instruments ${ }^{2,5,6}$. Composite measures, however, give rise to some concerns because a single measure that encompasses diverse domains might lose the ability to differentiate between activity in individual domains. At the OMERACT meeting (Outcome Measures in Rheumatology), it was emphasized that the use of any composite measure should permit the effect of an intervention on each domain to be assessed independently ${ }^{7}$.

Defining remission in PsA so that all these different dimensions can be identified remains elusive despite numerous attempts ${ }^{6}$. Minimal disease activity (MDA) has recently been defined as an achievable and acceptable goal ${ }^{8,9}$. A patient is classified as achieving MDA when meeting 5 of the following 7 criteria: tender joint count (TJC) $\leq 1$, swollen joint count (SJC) $\leq 1$; Psoriasis Activity and Severity Index $\leq 1$, or body surface area $\leq 3 \%$; patient's global assessment (PtGA) of pain $\leq 15 \mathrm{~mm}$ visual analog scale (VAS); PtGA of disease activity $\leq 20 \mathrm{~mm}$ VAS; disability index of the Health Assessment Questionnaire $\leq 0.5$; and tender entheseal points $\leq 1$.

In this issue of The Journal, Van den Bosch, et al $l^{10}$ present data on remission in patients with PsA treated with adalimumab in a 12-week open-label study. Only patients with initial active skin and joint disease were included in this analysis. At Week 12, of the 268 patients with active baseline disease, $64.9 \%$ achieved remission of joint and/or skin symptoms; $27.2 \%$ achieved joint remission (TJC $\leq 1+$ SJC $\leq 1$ ), irrespective of skin remission fulfillment; and skin remission (physician's global assessment $=$ clear/almost clear) irrespective of joint remission status was observed in $53.7 \%$ patients. Interestingly, among patients who met joint remission criteria (TJC $\leq 1$ and $\mathrm{SJC} \leq 1$ ), $83.2 \%$ of patients possessed an $\mathrm{SJC}=0$.

This study has some strengths: it was conducted in a large number of well-characterized patients; assessments were standardized and performed by trained evaluators (as in randomized clinical trials); and data on most patients were available for analysis. On the other hand, the study has some limitations: it was an open-label study, followup was for only 12 weeks, several domains of PsA such as enthesitis and dactylitis were not assessed, and a new, nonvalidated definition of remission was used. Data on 20 weeks are more biased because the continuation study not only is open label, but also includes very selected patients. Only patients with commercial availability of adalimumab and positive opinion of the investigator were included, biasing into selection of patients with good response.

With all this in mind, what new information is this study offering us? First, the study confirms that different remission criteria would give different results, even using criteria that assess only the joints. Second, the study shows that in PsA, as in RA, Disease Activity Score-28 remission criteria are less stringent than any of the other remission criteria and should probably not be used. Third, the study showed that

See PsA remission with ADA, page 952

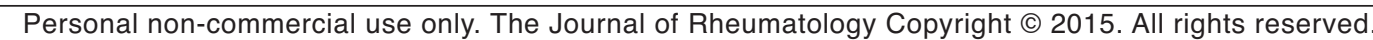


skin and joint responses do not always go hand in hand. Only $16 \%$ of patients achieved skin and joint remission at 12 weeks, while $27 \%$ achieved joint remission irrespective of skin remission, and $54 \%$ the other way round. Moreover, no correlation was identified when comparing improvement in skin disease activity with changes in joint disease. Once again, this feature emphasizes the importance of being able to evaluate the different domains separately when using composite measures, as mentioned above. Finally, the study showed that a very high percentage of patients achieving joint remission had no swollen joints. This important feature, although in some way flawed by the definition of remission itself ( $\leq 1$ swollen joint) in a way dispels the fear that patients achieving clinical remission or MDA might still have several swollen joints.

At first glance, the treatment data in this study might seem too low for a TNFi. They are, however, in the lower range of some similar studies, and this might be explained by patients' baseline characterisitics ${ }^{11,12,13,14}$.

The concept of remission implies disease control to the extent that disease sequelae are avoided and quality of life is maintained ${ }^{6}$. The definition of remission should be formulated in accordance with this statement. In fact, remission might be no more than a surrogate of future excellent functional status and quality of life, and thus should show an almost perfect correlation with the ultimate outcome. This has not yet been shown with any of the remission criteria studied in the Van den Bosch, et al article.

Along with these thoughts is that of the feature of subclinical activity (inflammation) detected using highly sensitive imaging techniques in patients with no clinical evidence of disease activity ${ }^{15}$. Do we need to include imaging remission in the definition of remission in PsA? Only more studies and time will tell, but for the time being, clinical features should guide our decisions.

We are getting closer but there is still a long way to go, and more research is needed. Studies like the present report by Van den Bosch show us that remission and near-remission states are achievable in PsA. There is, however, a need to define remission in a way that is acceptable for researchers, regulatory agencies, and patients; and that represents achieving a state that avoids disease progression and future damage, and maintains optimal function and normal quality of life.

ENRIQUE R. SORIANO, MD, MSC, Rheumatology Unit, Internal Medical Services, Hospital Italiano de Buenos Aires; and Fundacion Pedro M. Catoggio, Buenos Aires, Argentina.

Address correspondence to Dr. E.R. Soriano, Hospital Italiano de Buenos Aires, Sección Reumatología, Servicio de Clínica Médica,

Gascon 450, Buenos Aires 1181, Argentina.

E-mail: enrique.soriano@hospitalitaliano.org.ar

\section{REFERENCES}

1. Gladman DD. Early psoriatic arthritis. Rheum Dis Clin North Am 2012;38:373-86

2. Acosta Felquer ML, Ferreyra Garrott L, Marin J, Catay E, Scolnik $\mathrm{M}$, Scaglioni V, et al. Remission criteria and activity indices in psoriatic arthritis. Clin Rheumatol 2014;33:1323-30.

3. Gladman DD, Mease PJ, Strand V, Healy P, Helliwell PS, Fitzgerald $\mathrm{O}$, et al. Consensus on a core set of domains for psoriatic arthritis. J Rheumatol 2007;34:1167-70.

4. Schoels MM, Braun J, Dougados M, Emery P, Fitzgerald O, Kavanaugh A, et al. Treating axial and peripheral spondyloarthritis, including psoriatic arthritis, to target: results of a systematic literature search to support an international treat-to-target recommendation in spondyloarthritis. Ann Rheum Dis 2014; 73:238-42.

5. Caperon A, Helliwell PS. Remission in psoriatic arthritis. J Rheumatol Suppl. 2012 Jul;89:19-21.

6. Kavanaugh A, Fransen J. Defining remission in psoriatic arthritis. Clin Exp Rheumatol 2006;24(6 Suppl 43):S-83-7.

7. Coates LC, Fitzgerald O, Mease PJ, Gladman DD, Strand V, Goel N, et al. Development of a disease activity and responder index for psoriatic arthritis - report of the Psoriatic Arthritis Module at OMERACT 11. J Rheumatol 2014;41:782-91.

8. Coates LC, Fransen J, Helliwell PS. Defining minimal disease activity in psoriatic arthritis: a proposed objective target for treatment. Ann Rheum Dis 2010;69:48-53.

9. Coates LC, Helliwell PS. Validation of minimal disease activity criteria for psoriatic arthritis using interventional trial data. Arthritis Care Res 2010;62:965-9.

10. Van den Bosch F, Kavanaugh A, Kron M, Kupper H, Mease PJ. Clinical remission in patients with active psoriatic arthritis treated with adalimumab and correlations in joint and skin manifestations. J Rheumatol 2015;42:952-9.

11. Cantini F, Niccoli L, Cassara E, Kaloudi O, Nannini C. Duration of remission after halving of the etanercept dose in patients with ankylosing spondylitis: a randomized, prospective, long-term, follow-up study. Biologics 2013;7:1.

12. Cantini F, Niccoli L, Nannini C, Cassarà E, Pasquetti P, Olivieri I, et al. Frequency and duration of clinical remission in patients with peripheral psoriatic arthritis requiring second-line drugs. Rheumatology 2008;47:872-6.

13. Lindqvist UR, Alenius GM, Husmark T, Theander E, Holmström G, Larsson PT, et al. The Swedish early psoriatic arthritis register2-year followup: a comparison with early rheumatoid arthritis. J Rheumatol 2008;35:668-73.

14. Cantini F, Niccoli L, Cassara E, Kaloudi O, Nannini C. Sustained maintenance of clinical remission after adalimumab dose reduction in patients with early psoriatic arthritis: a long-term follow-up study. Biologics 2012;6:201-6.

15. Husic R, Gretler J, Felber A, Graninger WB, Duftner C, Hermann J, et al. Disparity between ultrasound and clinical findings in psoriatic arthritis. Ann Rheum Dis 2014;73:1529-36.

J Rheumatol 2015;42:907-8; doi:10.3899/jrheum.150331

Personal non-commercial use only. The Journal of Rheumatology Copyright @ 2015. All rights reserved. 